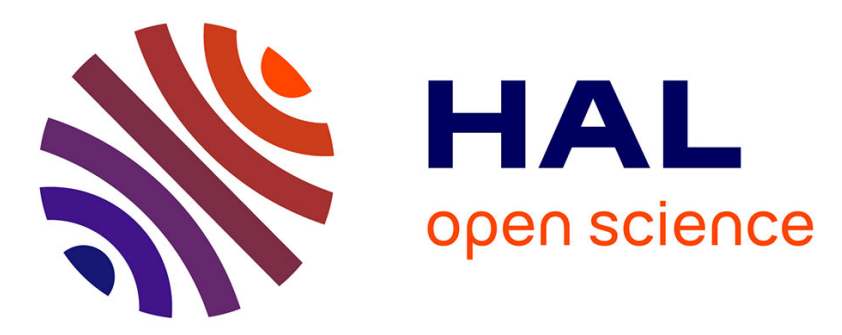

\title{
A Combined High Gain Observer and High-Order Sliding Mode Controller for a DFIG-Based Wind Turbine
}

\author{
Brice Beltran, Mohamed Benbouzid, Tarek Ahmed-Ali
}

\section{- To cite this version:}

Brice Beltran, Mohamed Benbouzid, Tarek Ahmed-Ali. A Combined High Gain Observer and HighOrder Sliding Mode Controller for a DFIG-Based Wind Turbine. 2010 IEEE International Energy Conference, Dec 2010, Manama, Bahrain. pp.322-327. hal-00598996

\section{HAL Id: hal-00598996 https://hal.science/hal-00598996}

Submitted on 8 Jun 2011

HAL is a multi-disciplinary open access archive for the deposit and dissemination of scientific research documents, whether they are published or not. The documents may come from teaching and research institutions in France or abroad, or from public or private research centers.
L'archive ouverte pluridisciplinaire HAL, est destinée au dépôt et à la diffusion de documents scientifiques de niveau recherche, publiés ou non, émanant des établissements d'enseignement et de recherche français ou étrangers, des laboratoires publics ou privés. 


\title{
A Combined High Gain Observer and High-Order Sliding Mode Controller for a DFIG-Based Wind Turbine
}

\author{
B. Beltran ${ }^{1}$, M.E.H Benbouzid ${ }^{1}$ and T. Ahmed-Ali ${ }^{2}$ \\ ${ }^{1}$ University of Brest, EA 4325 LBMS \\ Rue de Kergoat, CS 93837, 29238 Brest Cedex 03, France \\ ${ }^{2}$ Université de Caen, UMR CNRS 6072 GREYC \\ Campus Côte de Nacre, Boulevard du Maréchal Juin - BP 5186, 14032 Caen Cedex, France \\ brice.beltran@dga.defense.gouv.fr, Mohamed.Benbouzid@univ-brest.fr, Tarek.Ahmed-Ali@greyc.ensicaen.fr
}

\begin{abstract}
This paper deals with the power generation control in variable speed wind turbines. In this context, a control strategy is proposed to ensure power extraction optimization of a DFIGbased wind turbine. The proposed control strategy combines an MPPT using a high gain observer and second-order sliding mode for the DFIG control. This strategy presents attractive features such as chattering-free behavior, finite reaching time, robustness and unmodeled dynamics (generator and turbine).
\end{abstract}

The overall strategy has been validated on a $1.5-\mathrm{MW}$ threeblade wind turbine using the NREL wind turbine simulator FAST.

Index Terms -Wind turbine (WT), Doubly-Fed Induction Generator (DFIG), high gain observer, high-order sliding mode.

\section{NOMENCLATURE}

$v \quad=$ Wind speed;

$\rho \quad=$ Air density;

$R \quad=$ Rotor radius $(\mathrm{m})$;

$P_{a} \quad=$ Aerodynamic power;

$T_{a} \quad=$ Aerodynamic torque;

$\lambda=$ Tip speed ratio;

$C_{p} \quad=$ Power coefficient;

$\omega \quad=$ WT rotor speed;

$\omega_{m g} \quad=$ Generator speed;

$T_{g} \quad=$ Generator electromagnetic torque;

$J \quad=$ Turbine total inertia;

$K=$ Turbine total external damping;

$s(r) \quad=\quad$ Stator (rotor) index;

$d(q) \quad=$ Synchronous reference frame index;

$V(I) \quad=$ Voltage (current);

$P(Q) \quad=$ Active (reactive) power;

$\phi \quad=$ Flux;

$T_{e m} \quad=$ Electromagnetic torque;

$R \quad=$ Resistance;

$L(M) \quad=$ Inductance (mutual inductance);

$\sigma \quad=$ Leakage coefficient, $\sigma=1-M^{2} / L_{s} L_{r}$;

$\theta_{r} \quad=$ Rotor position;

$\omega_{r}\left(\omega_{s}\right)=$ Angular speed (synchronous speed);

$s \quad=$ Slip;

$p \quad=$ Pole pair number.

\section{INTRODUCTION}

Variable speed wind turbines are continuously increasing their market share, since it is possible to track the changes in wind speed by adapting shaft speed and thus maintaining optimal power generation. The more variable speed wind turbines are investigated, the more it becomes obvious that their behavior is significantly affected by the used control strategy. Typically, they use aerodynamic controls in combination with power electronics to regulate torque, speed, and power. The aerodynamic control systems, usually variable-pitch blades or trailing-edge devices, are expensive and complex, especially when the turbines are larger. This situation provides a motivation to consider alternative control approaches and to introduce more intelligence [1].

Therefore, this paper deals with power generation control in variable speed wind turbines. A control strategy is proposed to ensure power extraction optimization and reduce mechanical stresses in the drive train of a DFIG-based wind turbine. The proposed control strategy combines an MPPT using a high gain observer and second-order sliding mode for the DFIG control. This strategy presents attractive features such as chattering-free behavior, finite reaching time, robustness and unmodeled dynamics (generator and turbine).

The overall control strategy, illustrated by Fig. 1, has been validated on a 1.5 -MW three-blade wind turbine using the NREL wind turbine simulator FAST.

\section{WIND TURBINE MODELING}

The global scheme for a grid-connected wind turbine is given in Fig. 2. The wind turbine modeling is inspired from [2]. In the following, the wind turbine components models are briefly described.

\section{A. The Turbine Model}

In this case, the aerodynamic power $P_{a}$ captured by the wind turbine is given by

$P_{a}=\frac{1}{2} \pi \rho R^{2} C_{p}(\lambda) v^{3}$ 


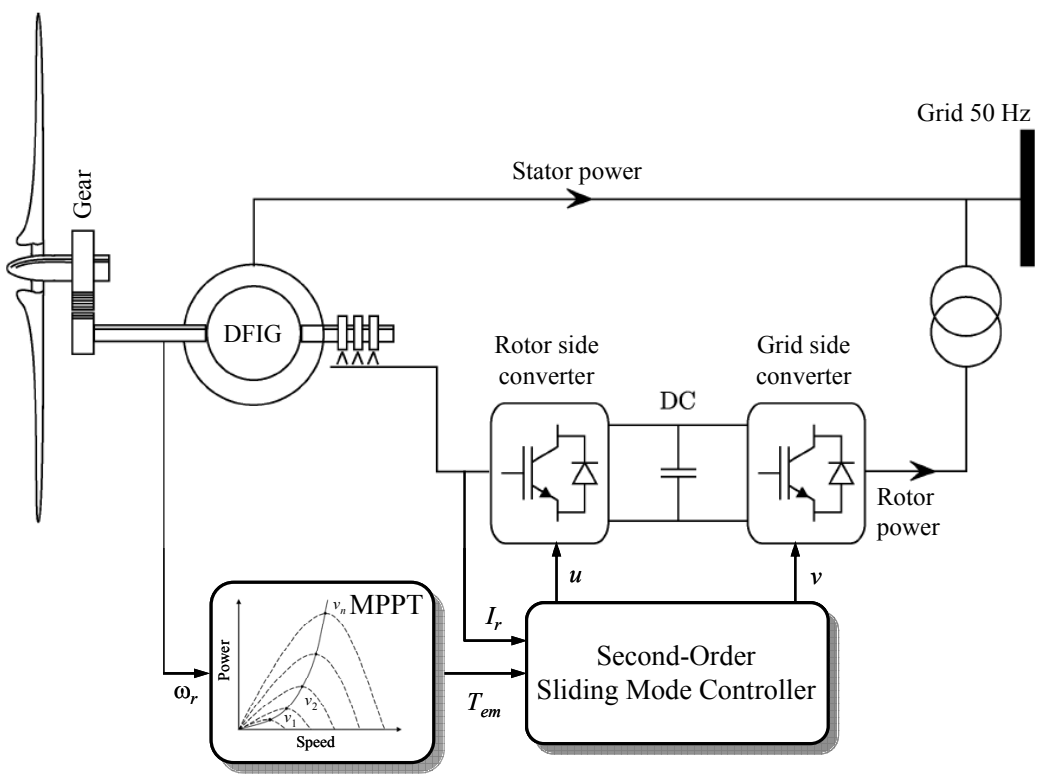

Fig. 1. The proposed control structure.

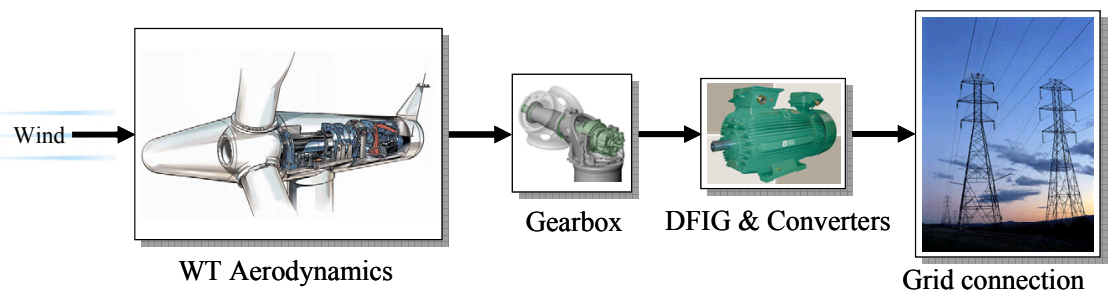

Fig. 2. Wind turbine global scheme.

where $\lambda=\frac{R \omega}{v}$

Normally, a variable speed wind turbine follows the $C_{p m a x}$ to capture the maximum power up to the rated speed by varying the rotor speed to keep the system at $\lambda_{\text {opt }}$. Then it operates at the rated power with power regulation during high wind periods by active control of the blade pitch angle or passive regulation based on aerodynamic stall.

The rotor power (aerodynamic power) is also defined by

$P_{a}=\omega T_{a}$

According to [4], the following simplified model is adopted for the turbine (drive train) for control purposes.

$$
J \dot{\omega}=T_{a}-K \omega-T_{g}
$$

\section{B. The Generator Model}

The WT adopted generator is the DFIG. DFIG-based WT will offer several advantages including variable speed operation ( $\pm 33 \%$ around the synchronous speed), and fourquadrant active and reactive power capabilities. Such system also results in lower converter costs (typically $25 \%$ of total system power) and lower power losses compared to a system based on a fully fed synchronous generator with full-rated converter. Moreover, the generator is robust and requires little maintenance [3].

The control system is usually defined in the synchronous $d$ $q$ frame fixed to either the stator voltage or the stator flux. For the proposed control strategy, the generator dynamic model written in a synchronously rotating frame $d-q$ is given by (5).

$\left\{\begin{array}{l}V_{s d}=R_{s} I_{s d}+\frac{d \phi_{s d}}{d t}-\omega_{s} \phi_{s q} \\ V_{s q}=R_{s} I_{s q}+\frac{d \phi_{s q}}{d t}+\omega_{s} \phi_{s d} \\ V_{r d}=R_{r} I_{r d}+\frac{d \phi_{r d}}{d t}-\omega_{r} \phi_{r q} \\ V_{r q}=R_{r} I_{r q}+\frac{d \phi_{r q}}{d t}+\omega_{r} \phi_{r d} \\ \phi_{s d}=L_{s} I_{s d}+M I_{r d} \\ \phi_{s q}=L_{s} I_{s q}+M I_{r q} \\ \phi_{r d}=L_{r} I_{r d}+M I_{s d} \\ \phi_{r q}=L_{r} I_{r q}+M I_{s q} \\ T_{e m}=p M\left(I_{r d} I_{s q}-I_{r q} I_{s d}\right)\end{array}\right.$

For simplification purposes, the $q$-axis is aligned with the stator voltage and the stator resistance is neglected [4]. These will lead to (6). 


$$
\left\{\begin{array}{l}
\frac{d I_{r d}}{d t}=\frac{1}{\sigma L_{r}}\left(v_{r d}-R_{r} I_{r d}+s \omega_{s} \sigma L_{r} I_{r q}-\frac{M}{L_{s}} \frac{d \phi_{s d}}{d t}\right) \\
\frac{d I_{r q}}{d t}=\frac{1}{\sigma L_{r}}\left(v_{r q}-R_{r} I_{r q}-s \omega_{s} \sigma L_{r} I_{r d}-s \omega_{s} \frac{M}{L_{s}} \phi_{s d}\right) \\
T_{e m}=-p \frac{M}{L_{s}} \phi_{s d} I_{r q}
\end{array}\right.
$$

\section{THE MPPT STRATEGY}

\section{A. Problem Formulation}

The reference torque of the MPPT block must address two problems: the captured power maximization and be driven according to the three fundamental operating regions illustrated by Fig. 3 .

In practice, there are two possible regions of turbine operation, namely the high- and low-speed regions. High speed operation (III) is frequently bounded by the speed limit of the machine. Conversely, regulation in the low-speed region (II) is usually not restricted by speed constraints. However, the system has nonlinear nonminimum phase dynamics in this region. This adverse behavior is an obstacle to perform the regulation task [5].

In region II, the control objective is to optimize the capture wind energy by tracking the optimal torque $T_{\text {opt }}$.

$T_{o p t}=k \omega^{2}$, with $k=\frac{1}{2} \pi \rho R^{5} \frac{C_{p \max }}{\lambda_{o p t}^{3}}$

The standard strategy neglect the dynamic of the drive train, which means that the aerodynamic torque is supposed to be equal to the generator torque. It is obvious that in many cases, and especially for turbulent winds, this assumption will not be realistic. The proposed control strategy relies then on the aerodynamic torque estimation using a high gain observer [6]. This estimate is then used to derive a high-order sliding mode controller that ensures $T_{\text {opt }}$ tracking in finite time.

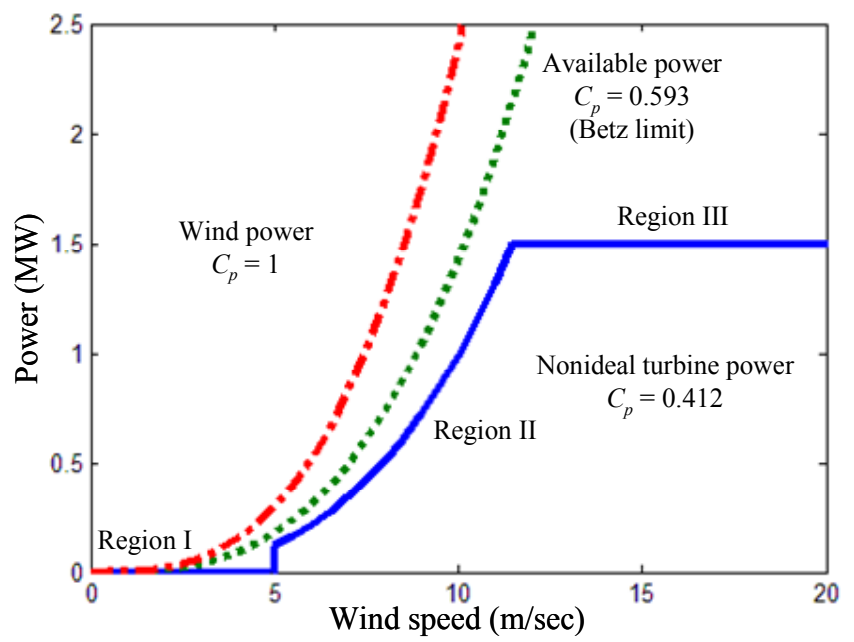

Fig. 4. Steady-state power curves.

\section{B. High Gain Observer}

A high gain observer will therefore be used to estimate the aerodynamic torque. A key feature of a high gain observer is that it will reduce the chattering induced by a sliding mode observer [6].

From (4), we have

$\dot{\omega}=\frac{T_{a}}{J}-\frac{K \omega}{J}-\frac{T_{e m}}{J}$

The following notations are introduced.

$\left\{\begin{array}{l}x_{1}=\omega \\ x_{2}=\frac{T_{a}}{J}\end{array}\right.$

Thus we have $x=\left\{\begin{array}{l}\dot{x}_{1}=x_{2}-\frac{K}{J} x_{1}-\frac{T_{e m}}{J} \\ \dot{x}_{2}=f(t)\end{array}\right.$

where

$A=\left[\begin{array}{ll}0 & 1 \\ 0 & 0\end{array}\right], C=\left[\begin{array}{ll}1 & 0\end{array}\right], \varphi(x, u)=\left[\begin{array}{c}\frac{-K x_{1}-u}{J} \\ 0\end{array}\right], \varepsilon(t)=\left[\begin{array}{c}0 \\ f(t)\end{array}\right]$,

or in matrix form $\left\{\begin{array}{l}\dot{x}=A x+\varphi(x, u)+\varepsilon(t) \\ y=C x\end{array}\right.$

A candidate observer could be [6]

$\dot{\hat{x}}=A \hat{x}+\varphi(\hat{x}, u)-\theta \Delta_{\theta}{ }^{-1} S^{-1} C^{T} C(\hat{x}-x)$

where $\Delta_{\theta}=\left[\begin{array}{ll}1 & 0 \\ 0 & \frac{1}{\theta}\end{array}\right], S=\left[\begin{array}{cc}1 & -1 \\ -1 & 2\end{array}\right]$

Let $S$ be the unique solution of the algebraic Lyapunov equation

$S+A^{T} S+S A-C^{T} C=0$

Let us define $\bar{x}=\Delta_{\theta}(\hat{x}-x)$

then $\dot{\bar{x}}=\theta\left(A-S^{-1} C^{T} C\right) \bar{x}+\Delta_{\theta}(\varphi(\hat{x})-\varphi(x))-\Delta_{\theta} \varepsilon(t)$

Consider the quadratic function

$V=\bar{x}^{T} S x$

then 


$$
\left\{\begin{array}{l}
\dot{V}=2 \bar{x} S \dot{\bar{x}} \\
\dot{V}=-\theta V-\bar{x}^{T} C^{T} C \bar{x}+2 \bar{x}^{T} S \Delta_{\theta}(\varphi(\hat{x})-\varphi(x))-2 \bar{x}^{T} S \Delta_{\theta} \bar{\varepsilon}(t)
\end{array}\right.
$$

Therefore

$$
\dot{V} \leq-\theta V+2\|\bar{x}\| \lambda_{\max }(S)\left(\left\|\Delta_{\theta}(\varphi(\hat{x})-\varphi(x))\right\|+\left\|\Delta_{\theta} \bar{\varepsilon}(t)\right\|\right)
$$

We can assume that (triangular structure and the Lipschitz assumption on $\varphi$ )

$$
\left\{\begin{array}{l}
\left\|\Delta_{\theta}(\varphi(\hat{x})-\varphi(x))\right\| \leq \xi\|\bar{x}\| \\
\|f(t)\| \leq \delta
\end{array} \text { with } \xi=\frac{K}{J}\right.
$$

It comes that $\dot{V} \leq-\theta V+2\|\bar{x}\|^{2} \lambda_{\text {max }}(S) \xi+2\|\bar{x}\| \lambda_{\text {max }}(S) \frac{\delta}{\theta}$

then $\dot{V} \leq-\theta V+c_{1} V+c_{2} \frac{\delta}{\theta} \sqrt{V}$

with $\left\{\begin{array}{l}c_{1}=2 \frac{\lambda_{\text {max }}(S)}{\lambda_{\text {min }}(S)} \xi \\ c_{2}=2 \frac{\lambda_{\text {max }}(S)}{\sqrt{\lambda_{\text {min }}(S)}}\end{array}\right.$

Now taking

$$
\left\{\begin{array}{l}
\theta_{0}=\max \left\{1, c_{1}\right\} \\
\lambda=\sqrt{\frac{\lambda_{\text {max }}(S)}{\lambda_{\text {min }}(S)}} \\
\mu_{\theta}=\frac{\theta-c_{1}}{2} \\
M_{\theta}=2 \frac{\lambda_{\text {max }}(S)}{\lambda_{\text {min }}(S)\left(\theta-c_{1}\right)}
\end{array}\right.
$$

and $\theta>\theta_{0}$, we obtain

$$
\|e(t)\| \leq \theta \lambda \exp \left(-\mu_{\theta} t\right)\|e(0)\|+M_{\theta} \delta
$$

With $\hat{T}_{a}=J \hat{x}_{2}$, it comes that

$$
\tilde{T}_{a}=\hat{T}_{a}-T_{a} \leq J\left[\theta \lambda \exp \left(-\mu_{\theta} t\right)\|e(0)\|+M_{\theta} \delta\right]
$$

A practical estimate of the aerodynamic torque is then obtained as $M_{\theta}$ decreases when $\theta$ increases. The asymptotic estimation error can be made as small as desired by choosing high enough values of $\theta$. However, very large values of $\theta$ are to be avoided in practice since the estimator may become noise sensitive.
Now, the control objective can be formulated by the following tracking errors

$$
e_{T}=T_{o p t}-T_{a}
$$

where $T_{a}$ is observed. Then we will have

$$
\dot{e}_{T}=2 k_{o p t} \omega\left(T_{a}-K_{t} \omega-T_{g}\right)-\dot{T}_{a}
$$

If we define the following functions

$\left\{\begin{array}{l}F=2 k_{o p t} \omega \\ G=2 k_{o p t} \omega\left(T_{a}-K_{t} \omega\right)-\dot{T}_{a}\end{array}\right.$

then $\ddot{e}_{T}=-F \dot{T}_{g}+\dot{G}$

Let us consider the following observer based on the supertwisting algorithm [7].

$$
\left\{\begin{array}{l}
T_{g}=y+B_{1}\left|e_{T}\right|^{\frac{1}{2}} \operatorname{sgn}\left(e_{T}\right) \\
\dot{y}=+B_{2} \operatorname{sgn}\left(e_{T}\right)
\end{array}\right.
$$

The gains $B_{1}$ and $B_{2}$ are chosen as

$$
\left\{\begin{array}{l}
B_{1}>\frac{\Phi_{2}}{\Gamma_{m}} \\
B_{2}{ }^{2} \geq \frac{4 \Phi_{2} \Gamma_{M}\left(A_{1}+\Phi_{1}\right)}{\Gamma_{m}^{3}\left(A_{1}-\Phi_{1}\right)} \\
|\dot{G}|<\Phi_{2} \\
0<\Gamma_{m} \leq F \leq \Gamma_{M}
\end{array}\right.
$$

Thus we will guaranty the convergence of $e_{\mathrm{T}}$ to 0 in a finite time $t_{c}$. The aerodynamic torque estimation is then deduced.

$T_{a}=T_{o p t}, t>t_{c}$

\section{CONTROL OF THE DFIG-BASED WIND TURBINE}

The DFIG-based WT control objective is to optimize the extracted power by tracking the optimal torque $T_{o p t}(7)$. The control is a compromise between conversion efficiency and torque oscillation smoothing [8].

The reactive power is expressed as follows.

$Q_{s}=V_{s q} I_{s d}-V_{s d} I_{s q}$

Adapting (25) to our hypotheses, it comes then

$Q_{s}=\frac{V_{s} \phi_{s}}{L_{s}}-\frac{V_{s} M}{L_{s}} I_{r d}$ 
As the stator reactive power reference is zero, then

$\phi_{s}=\frac{V_{s}}{\omega_{s}} \rightarrow I_{r d_{-} r e f}=\frac{V_{s}}{\omega_{s} M}$

Let us consider the following tracking errors.

$\left\{\begin{array}{l}e_{I_{r d}}=I_{r d}-I_{r d_{-} r e f} \\ e_{T_{e m}}=T_{e m}-T_{r e f}\end{array}\right.$

Then we will have

$\left\{\begin{array}{l}\dot{e}_{I_{r d}}=\frac{1}{\sigma L_{r}}\left(V_{r d}-R_{r} I_{r d}+g \omega_{s} L_{r} \sigma I_{r q}-\frac{M}{L_{s}} \frac{d \phi_{s d}}{d t}\right)-\dot{I}_{r d_{-} r e f} \\ \dot{e}_{T_{e n}}=-p \frac{M}{\sigma L_{s} L_{r}} \phi_{s}\left(\begin{array}{l}V_{r q}-R_{r} I_{r q}-g \omega_{s} L_{r} \sigma i_{r d} \\ -g \omega_{s} \frac{M}{L_{s}} \phi_{s d}\end{array}\right)-\dot{T}_{r e f}\end{array}\right.$

If we define the functions $G_{1}$ and $G_{2}$ as follows.

$$
\left\{\begin{array}{l}
G_{1}=\frac{1}{\sigma L_{r}}\left(g \omega_{s} \sigma L_{r} I_{r q}-\frac{M}{L_{s}} \frac{d \phi_{s d}}{d t}\right)-\dot{I}_{r d-r e f} \\
G_{2}=-p \frac{M}{\sigma L_{s} L_{r}} \phi_{s}\left(-g \omega_{s} \sigma L_{r} I_{r d}-g \omega_{s} \frac{M}{L_{s}} \phi_{s d}\right)-\dot{T}_{r e f}
\end{array}\right.
$$

Thus we have

$$
\left\{\begin{array}{l}
\ddot{e}_{I_{r d}}=\frac{1}{\sigma L_{r}} \dot{V}_{r d}+\dot{G}_{1}-\frac{1}{\sigma L_{r}} R_{r} \dot{I}_{r d} \\
\ddot{e}_{\Gamma_{e m}}=-p \frac{M}{\sigma L_{s} L_{r}} \phi_{s} \dot{V}_{r q}+\dot{G}_{2}+p \frac{M}{\sigma L_{s} L_{r}} \phi_{s} R_{r} \dot{I}_{r q}
\end{array}\right.
$$

Now, lets us consider the following high-order sliding mode controller based on the supertwisting algorithm.

$$
\left\{\begin{array}{l}
V_{r q}=y_{1}+B_{1}\left|e_{T_{e n}}\right|^{\frac{1}{2}} \operatorname{Sgn}\left(e_{T_{e n}}\right)+\frac{1}{\sigma L_{r}} R_{r} I_{r d} \\
\dot{y}_{1}=+B_{2} \operatorname{Sgn}\left(e_{T_{e m}}\right) \\
V_{r d}=y_{2}-B_{3}\left|e_{I_{r d}}\right|^{\frac{1}{2}} \operatorname{Sgn}\left(e_{I_{r d}}\right)-p \frac{M}{\sigma L_{s} L_{r}} \phi_{s} R_{r} I_{r q} \\
\dot{y}_{2}=-B_{4} \operatorname{Sgn}\left(e_{I_{r d}}\right)
\end{array}\right.
$$

Where the constants $B_{1}, B_{2}, B_{3}, B_{4}, \Phi_{1}$, and $\Phi_{2}$ satisfy (32).

Thus, we can assert that there exist finite times $t_{\text {Tem }}$ and $t_{\text {Ird }}$ leading to (33).

This means that the control objective is achieved.

$$
\begin{aligned}
& || \dot{G}_{1} \mid<\Phi_{1} \\
& B_{1}>p \frac{M}{\sigma L_{s} L_{r}} \phi_{s} \Phi_{1}, B_{2}^{2} \geq \frac{4 \Phi_{1}\left(B_{1}+\Phi_{1}\right)}{\sigma^{2} L_{r}^{2}\left(B_{1}-\Phi_{1}\right)} \\
& \left|\dot{G}_{2}\right|<\Phi_{2} \\
& B_{3}>\frac{\Phi_{2}}{\sigma L_{r}}, B_{4}{ }^{2} \geq \frac{4 \Phi_{2}\left(B_{3}+\Phi_{2}\right)}{\sigma^{2} L_{r}{ }^{2}\left(B_{3}-\Phi_{2}\right)} \\
& \begin{cases}I_{r d_{-} r e f}=I_{r d}, & \forall t>t_{I_{r d}} \\
T_{r_{e f}}=T_{e m}, & \forall t>t_{T_{e m}}\end{cases}
\end{aligned}
$$

\section{VALIDATION RESULTS WITH FAST}

The proposed SOSM control strategy has been tested for validation using the NREL FAST code [2], [9]. An interface has been developed between FAST and Matlab-Simulink ${ }^{\circledR}$ enabling users to implement advanced turbine controls in Simulink convenient block diagram form.

Numerical validations, using FAST with MatlabSimulink ${ }^{\circledR}$ have been carried out on the NREL WP 1.5-MW wind turbine using turbulent FAST wind data shown by Fig. 3 [10]. The wind turbine, the DFIG ratings, and control parameters are given in the Appendix.

The observer validation is clearly illustrated by Fig. 4 . Indeed, the aerodynamic torque tracks efficiently the optimal torque. As shown in Figs. 6 and 7, very good tracking performances are achieved in terms of DFIG rotor current and WT torque with respect to wind fluctuations. The proposed control strategy does not induce increased mechanical stress as there are no strong torque variations.

The proposed control strategy that combines a high gain observer-based MPPT and a second-order sliding mode has been compared to classical techniques used in wind power industry. The first one is that using the active power as reference and leading to the following control reference [11].

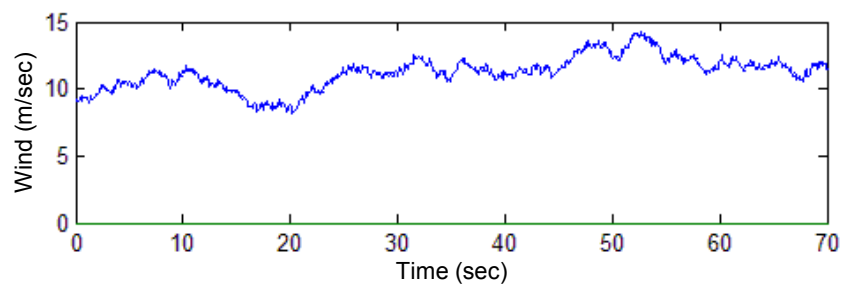

Fig. 3. Wind speed profile.

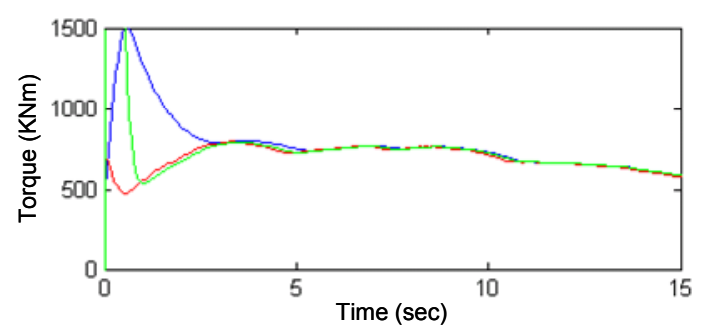

Fig. 4. Aerodynamic torque: $T_{\text {opt }}$ (blue), $T_{a}$ real (red), $T_{a}$ observed (green). 


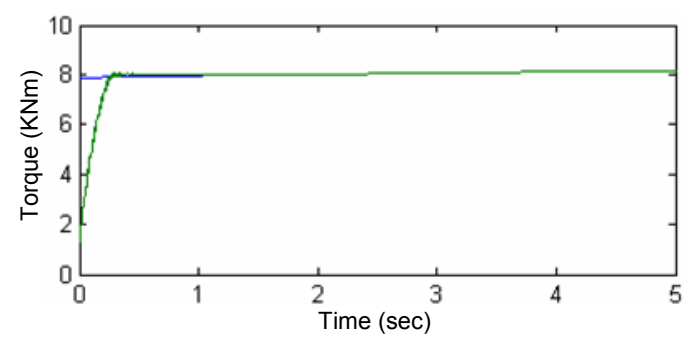

Fig. 6. Torque tracking performance: Reference (blue) and real (green).

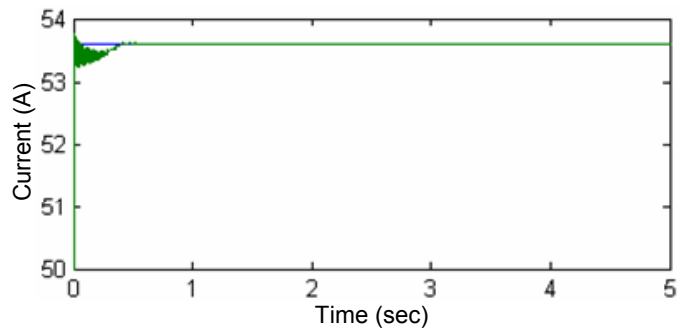

Fig. 7. Current $I_{r d}$ tracking performance: Reference (blue) and real (green)

$I_{r q_{-} r e f}=-\frac{L_{s}}{V_{s} M} P_{r e f}$

This approach supposes that the active power is equal to the generator power. This approximation drives a difference between the desired torque and the generated one (Fig. 8).

The second classical approach is the one using the following reference [12].

$$
I_{r q_{-} r e f}=-\frac{L_{s}}{p M \phi_{s}} T_{r e f}
$$

In this case, bad tracking performances are also achieved (Fig. 9).

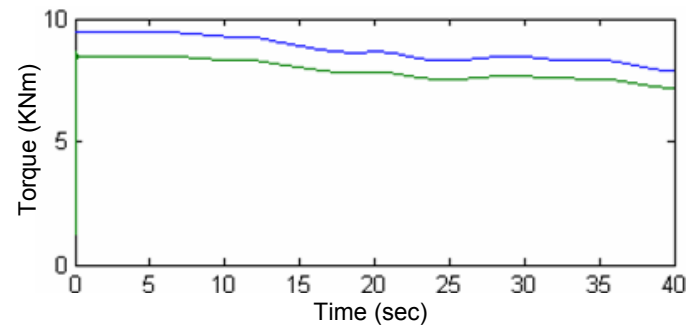

Fig. 8. Torque: Reference (blue) and real (green).

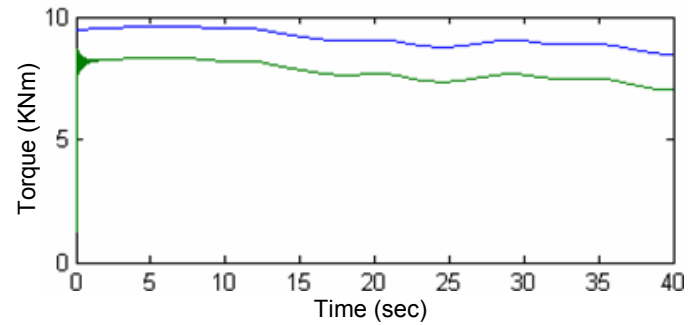

Fig. 9. Torque: Reference (blue) and real (green).

\section{CONCLUSION}

This paper dealt with a second-order sliding mode control of a doubly-fed induction-based wind turbine combined with a high gain observer-based MPPT. The proposed control strategy has been tested using the NREL FAST simulator on a $1.5-\mathrm{MW}$ wind turbine.

\section{APPENDIX}

CHARACTERISTICS OF THE SIMULATED WIND TURBINE

\begin{tabular}{c|c}
\hline \hline Number of blades & 3 \\
\hline Rotor diameter & $70 \mathrm{~m}$ \\
\hline Hub height & $84.3 \mathrm{~m}$ \\
\hline Rated power & $1.5 \mathrm{MW}$ \\
\hline Turbine total inertia & $4.4532 \times 10^{5} \mathrm{~kg} \mathrm{~m}^{2}$ \\
\hline \hline
\end{tabular}

PARAMETERS OF THE SIMULATED DFIG

$R_{s}=0.005 \Omega, L_{s}=0.407 \mathrm{mH}, R_{r}=0.0089 \Omega, L_{r}=0.299 \mathrm{mH}$ $M=0.0016 \mathrm{mH}, p=2$

CONTROL PARAMETERS

$\theta=30, A_{1}=5 \times 10^{3}, A_{2}=1 \times 10^{5}, B_{1}=1.5, B_{2}=50, B_{3}=200, B_{3}=1000$ $k_{\text {opt }}=1.6124 \times 10^{5}$

\section{REFERENCES}

[1] F.D. Bianchi et al. Wind Turbine Control Systems. Principles, Modelling and Gain Scheduling Design. London: Springer 2007.

[2] B. Beltran et al., "High-order sliding mode control of variable speed wind turbines," IEEE Trans. Industrial Electronics, vol. 56, n9, pp. 3314-3321, September 2009

[3] M.E.H. Benbouzid et al., "The state of the art of generators for wind energy conversion systems," in Proceedings of ICEM'06, Chania, Crete Island, Greece, September 2006.

[4] S. Müller and al., "Doubly fed induction generator systems," IEEE Industry Applications Magazine, vol. 8, n³, pp. 26-33, May-June 2002.

[5] T. Senjyu et al., "Output power leveling of wind turbine Generator for all operating regions by pitch angle control," IEEE Trans. Energy Conversion, vol. 21, n², pp. 467-475, June 2006.

[6] M. Farza et al., "Observer design for a class of MIMO nonlinear systems," Automatica, vol. 40, n¹, pp. 135-143, September 2004.

[7] A. Levant and al., "Integral high-order sliding modes," IEEE Trans. Automatic Control, vol. 52, n7, pp. 1278-1282, July 2007.

[8] H. de Battista and al., "Sliding mode control of wind energy systems with DOIG-power efficiency and torsional dynamics optimization,' IEEE Trans. Power Systems, vol. 15, n², pp. 728-734, May 2000.

[9] http://wind.nrel.gov/designcodes/simulators/fast/.

[10] M.M. Hand et al., "Advanced control design and field testing for wind turbines at the National Renewable Energy Laboratory," NREL/CP500-36118, May 2004

[11] F. Poitiers et al., "Advanced control of a doubly-fed induction generator for wind energy conversion," Electric Power Systems Research, doi:10.1016/j.epsr.2009.01.007, 2009.

[12] R. Cardenas et al., "Sensorless vector control of induction machines for variable-speed wind energy applications," IEEE Trans. Energy Conversion, vol. 19, n 1, pp. 196-205, March 2004. 